\title{
BMJ Open Magnitude of preterm hospital neonatal mortality and associated factors in northern Ethiopia: a cross- sectional study
}

\author{
Bekahegn Girma (1) , Jemberu Nigussie
}

To cite: Girma B, Nigussie J. Magnitude of preterm hospital neonatal mortality and associated factors in northern Ethiopia: a crosssectional study. BMJ Open 2021;11:e051161. doi:10.1136/ bmjopen-2021-051161

- Prepublication history for this paper is available online. To view these files, please visit the journal online (http://dx.doi. org/10.1136/bmjopen-2021051161).

Received 13 March 2021 Accepted 08 November 2021

Check for updates

(c) Author(s) (or their employer(s)) 2021. Re-use permitted under CC BY-NC. No commercial re-use. See rights and permissions. Published by BMJ.

Department of Nursing, College of Medicine and Health Science, Dilla University, Dilla, Ethiopia

Correspondence to

Bekahegn Girma;

Bekahegng@du.edu.et

\section{ABSTRACT}

Objective This study aimed to assess the magnitude of preterm neonatal mortality in hospitals and associated factors in northern Ethiopia.

Design Institutional-based cross-sectional study. Setting Comprehensive specialised hospitals in the Tigray region, northern Ethiopia.

Participants Preterm neonates admitted in Ayder and Aksum comprehensive specialised hospitals

Primary outcome Magnitude of preterm neonatal mortality.

Secondary outcome Factors associated with preterm neonatal mortality

Result This study was conducted from 1 April 2019 to 15 May 2019 among 336 participants with a response rate of $96.8 \%$. The magnitude of preterm neonatal mortality was $28.6 \%$ (95\% Cl: 24.0 to 33.7$)$. In multivariable logistic regression, respiratory distress syndrome (adjusted odd ratio $(\mathrm{AOR})=2.85 ; 95 \% \mathrm{Cl}: 1.35$ to 6.00$)$, apnoea of prematurity (AOR=5.45; $95 \% \mathrm{Cl}: 1.32$ to 22.5$)$, nulli parity (AOR=3.63; $95 \% \mathrm{Cl}: 1.59$ to 8.24 ) and grand parity ( $A O R=3.21 ; 95 \% \mathrm{Cl}: 1.04$ to 9.94 ) were significant factors associated with preterm neonatal mortality. However, receiving Kangaroo mother care $(\mathrm{AOR}=0.08 ; 95 \% \mathrm{Cl}$ : 0.03 to 0.20 ) and feeding initiated during hospitalisation ( $A 0 R=0.07 ; 95 \% \mathrm{Cl}: 0.03$ to 0.15 ) were protective against preterm neonatal mortality.

Conclusions The magnitude of preterm neonatal mortality in hospitals was still high. Interventions geared towards curbing preterm in-hospital neonatal mortality should strengthen early diagnosis and treatment of preterm newborns with respiratory distress syndrome and apnoea of prematurity; while concomitantly reinforcing the implementation of kangaroo care and early feeding initiation is important

\section{INTRODUCTION}

In the world, preterm-related complications are the leading causes of neonatal mortality ${ }^{1}$; especially in low-income and middle-income countries (LMICs). ${ }^{1-3}$ The global rate of neonatal mortality is 18 deaths per 1000 live births; $35 \%$ due to prematurity. ${ }^{2}$ According to the WHO report, $81.1 \%$ of preterm births occur in LMICs, this is due to low quality of care for pregnant mothers. ${ }^{45}$ Moreover, the
Strengths and limitations of this study

- As strength, the study addressed all comprehensive specialised hospitals found in the Tigray region, Ethiopia.

- The study results were presented using veracious statistical methods.

- Due to the cross-sectional nature of the study design, we are unable to establish cause-effect relationships.

neonatal mortality ranges from $19.9 \%$ to $69 \% .{ }^{67}$ In sub-Saharan Africa and South Asia, prematurity is responsible for 0.75 million deaths of under 5 years of age; but the reduction rate of neonatal mortality is very low. ${ }^{1}$

Preterm newborns (born before 37 completed weeks of gestation $)^{8}$ had high risk of mortality ${ }^{910}$ and morbidity ${ }^{11}$ as compared with full-term newborns. Studies showed that preterm newborns are more vulnerable to organ failure, neurodevelopmental and learning impairment, visual disorders and long-term cardiovascular and noncommunicable diseases. ${ }^{12-14}$ Prematurity is responsible for $3.1 \%$ of the disability-adjusted life years occurring worldwide. ${ }^{15}$ Moreover, it is a major contributor to the loss of human potential ${ }^{16}$ and hospital admission. ${ }^{17}$

To achieve the global sustainable development goal (SDG) of decreasing the neonatal mortality rate and mortality of under 5 to at least 12 and 25 deaths per 1000 live births, respectively by $2030,{ }^{18}$ better preventions and treatments of the leading causes of mortality are necessary. Furthermore, the WHO designed different strategies including essential newborn care, neonatal resuscitation, Kangaroo mother care (KMC), treatment of premature babies with complications and comprehensive neonatal intensive care. $^{13} 1920$ Even though, previous studies 
identified respiratory distress syndrome (RDS), asphyxia, maternal residency, gestational age, birth weight, jaundice, hypothermia, neonatal sepsis and maternal chronic disease $^{21-32}$ as a factors of mortality, preterm neonatal death remains a global burden. ${ }^{33}$

In Ethiopia, approximately $42 \%$ of mortality among under 5 is attributed to neonatal deaths. ${ }^{34}$ Although the federal health ministry designed and implemented different strategies such as antenatal care (ANC) service and family planning service to prevent preterm birth and also in 2015 developed another strategy to reduce neonatal mortality, ${ }^{35}$ preterm mortality is still high in our country. ${ }^{36}$ According to the Ethiopian Mini Demographic Health Survey (EDHS) 2019 report, the neonatal mortality rate is $30 \%,{ }^{37}$ which is increased from EDHS 2016 report $(29 \%) .^{38}$

To facilitate the reduction rate of this mortality, extensive and ongoing studies are needed to identify factors. However, in Ethiopia little is known about the magnitude of preterm in hospital neonatal mortality and its associated factors. Therefore, to support the achievement of the SDG plan, we aimed to assess the magnitude of preterm neonatal mortality in the hospitals and its associated factors in northern Ethiopia.

\section{METHODS AND MATERIALS}

\section{Study setting and design}

An institutional-based cross-sectional study was conducted from 1 April 2019 to 15 May 2019 in the comprehensive specialised hospitals of Ayder and Aksum, Tigray, Ethiopia. The Tigray region is one of the nine federal administrative regions in Ethiopia and has two comprehensive specialised hospitals. The Tigray region has an estimated total population of 5377 144: 2651167 males and 2725 977 females. Among the total population, 159164 are under 1 year of age. There are 2 comprehensive specialised hospitals, 15 general hospitals, 23 primary hospitals, 245 health centres and 750 health posts. ${ }^{39}$

Ayder comprehensive specialised hospital provides its service to more than 9 million people in its catchment areas of the Tigray, Afar and northern parts of the Amhara regional state. It has a total capacity of about 500 inpatient beds in all departments and other specialty units, including 45 neonatal beds in the neonatal intensive care unit (NICU) and more than 170000 patient flows per year. The hospital has more than 2165 staffs. Aksum comprehensive specialised hospital provides its service to a population of over 3.6 million from the central, northwest and western zones of the Tigray regional state. It has a total capacity of 173 beds, including 13 neonatal beds.

\section{Source and study population}

All preterm neonates admitted in Ayder and Aksum comprehensive specialised hospitals were source population. The study population was preterm neonates admitted in these hospitals from 1 February 2017 to 30 January 2019.

\section{Eligibility criteria}

Neonates born before their 37 weeks of gestation were included in this study.

Preterm newborns with an incomplete record for the outcome variable were excluded.

\section{Sample size determination and sampling technique}

The sample size was estimated using a single population proportion formula with a CI of $95 \%, \alpha=0.05$, and $\mathrm{p}=28.8 \%$ taken from a study conducted in Gonder, Ethiopia. ${ }^{40}$ By considering a $10 \%$ non-response rate, the total sample was 347. A total of 1242 preterm neonates were admitted to these hospitals from 1 February 2017 to 30 January 2019. Participants were proportionally selected using a simple random sampling technique from both hospitals.

\section{Operational definitions}

RDS: which is characterised by grunting while breathing, rapid or shallow breathing, and flaring of the nostrils. ${ }^{41}$

Apnoea of prematurity: respiratory pauses $>20 \mathrm{~s}$ or pauses $<20$ s that are related to bradycardia ( $<80$ beats/ $\min$ ), central cyanosis and/or oxygen saturation $<85 \%$ in neonates born at $<37$ weeks gestation and without causal disorders that induce apnea. ${ }^{41}$

Perinatal asphyxia: an Apgar score that remained less than 7 (at 5 min after birth) and evidence of acute hypoxic compromise with acidaemia. ${ }^{42}$

\section{Data collection procedure and tool}

The lists of participants were obtained from NICU health management system registration book. To collect the data from the charts, we used a pretested adapted English version data extraction checklist. Lastly, the data were scouted by two data collectors from randomly selected charts.

\section{Data quality control}

We conducted a pretest on 5\% (15) of the sample in Mekelle General Hospital. A single imputation was used to manage missing values. After 2 days of training, two data collectors (BSc nurses) and one supervisor (MSc in paediatrics and child health nursing) participated in the data collection. The twofold data entry was done and the consistency of the entered data was verified by comparing the two distinctly entered data. The content validity and inter-rater reliability tests were conducted to check the validity and reliability of the tool, respectively.

\section{Data processing and analysis}

Data were coded and entered by Epi-Data manager V.4.4.2.1 and exported to Stata statistical software V.14 for clearance and analysis. Descriptive statistics frequency and percentage were conducted. Bivariate and multivariable analysis was performed to see the statistical association between the outcome and independent variables. Factors with a $\mathrm{p}$ value $<0.2$ in the bivariate analysis were entered into multivariable logistic regression. Variables with a $\mathrm{p}$ value $<0.05$ in multivariable analysis were considered 
statistically significant factors. Lastly, we used an adjusted OR with $95 \%$ CI to determine the association.

\section{Patient and public involvement}

The patient and/or the public were not involved in the design, development, analysis and publication of this study.

\section{RESULT}

Of 347 preterm newborns, 336 were eligible and included in this study with a response rate of $96.8 \%$.

\section{Neonatal, maternal and obstetric-related characteristics}

Two hundred and eighty-one $(83.63 \%)$ mothers delivered in the hospital. Two hundred and sixty nine $(80.06 \%)$ mothers were found in the age range of 20-35 years; a median age of 27 years (IQR: 22-30). One hundred and eighty five $(55.06 \%)$ mothers were primipara and $330(98.21 \%)$ mothers had follow-up of ANC. Only 34 (10.12\%) mothers had obstetric complications during their index pregnancy (table 1).

Among 336 preterm newborns, 191 (56.85\%) were males and $260(77.38 \%)$ were within gestational age between 28 and 32 weeks; but not including 32. Feeding was initiated for $218(64.88 \%)$ of preterm newborns during their hospital stay and only $118(35.12 \%)$ of the neonates received KMC. Three hundred and nine $(91.96 \%)$ neonates had low birth weight $(<2500$ gram $)$ and approximately $147(43.75 \%)$ and $242(72.02 \%)$ preterm neonates had RDS and sepsis, respectively (table 2).

\section{Magnitude of preterm hospital neonatal mortality}

In this study, the magnitude of preterm in-hospital neonatal mortality was 28.6 with $95 \%$ CI (24.0 to 33.7). Among the neonates who died, 88 (91.7\%) of them were within the first 7 days of life.

\section{Factors associated with preterm neonatal mortality}

In the bivariate analysis gestational age, KMC, feeding status, birth weight, maternal residency, hypoglycaemic at admission, sepsis, RDS, parity and apnoea of prematurity were significantly associated with preterm neonatal mortality. However, in the multivariable analysis RDS, parity, KMC, feeding status and apnoea of prematurity were still statistically significant factors.

The odds of mortality for preterm newborns who received feeding during their hospital stay were reduced by $93 \%$ (adjusted odd ratio $(\mathrm{AOR})=0.07 ; 95 \% \mathrm{CI}$ : 0.03 to 0.15 ) compared with their counterparts. Similarly, providing KMC reduces the risk of death by $92 \%$ (AOR $=0.08 ; 95 \%$ CI: 0.03 to 0.20 ) compared with their comparison group. Preterm newborns diagnosed with RDS and apnoea of prematurity had $2.8 \quad(\mathrm{AOR}=2.85$; 95\% CI: 1.35 to 6.00$)$ and 5.4 times (AOR $=5.45 ; 95 \%$ CI: 1.32 to 22.5 ) higher mortality risk compared with their opposite groups, respectively. Furthermore, neonates born to nulliparous mothers had 3.6 times higher risk
Table 1 Sociodemographic and obstetric characteristics related to mothers of preterm newborns admitted to the NICU of the Ayder and Aksum comprehensive specialised hospitals, northern Ethiopia, 2019 ( $n=336)$

\begin{tabular}{|c|c|c|}
\hline Characteristics & Frequency & Per cent \\
\hline \multicolumn{3}{|l|}{ Maternal age in years } \\
\hline Less than 20 & 27 & 8.04 \\
\hline Between 20 and 35 & 269 & 80.06 \\
\hline 35 and above & 40 & 11.90 \\
\hline \multicolumn{3}{|l|}{ Place of delivery } \\
\hline Home & 16 & 4.76 \\
\hline Health centre & 39 & 11.61 \\
\hline Hospital & 281 & 83.63 \\
\hline \multicolumn{3}{|l|}{ Maternal residency } \\
\hline Urban & 191 & 56.85 \\
\hline Rural & 145 & 43.15 \\
\hline \multicolumn{3}{|l|}{ Parity } \\
\hline Nulli parity & 185 & 55.06 \\
\hline Multiparty & 111 & 33.04 \\
\hline Grand parity & 40 & 11.90 \\
\hline \multicolumn{3}{|l|}{ ANC visit } \\
\hline One & 5 & 1.5 \\
\hline Two & 39 & 11.6 \\
\hline Three & 161 & 47.9 \\
\hline Four and above & 122 & 36.3 \\
\hline \multicolumn{3}{|l|}{ Type of pregnancy } \\
\hline Singleton & 196 & 58.33 \\
\hline Multiple & 140 & 41.67 \\
\hline \multicolumn{3}{|l|}{ Mode of delivery } \\
\hline $\begin{array}{l}\text { Spontaneous vaginal } \\
\text { delivery }\end{array}$ & 268 & 79.76 \\
\hline Caesarean section & 68 & 20.24 \\
\hline \multicolumn{3}{|c|}{$\begin{array}{l}\text { Obstetric-related complication during index } \\
\text { pregnancy }\end{array}$} \\
\hline Yes & 34 & 10.12 \\
\hline No & 302 & 89.88 \\
\hline \multicolumn{3}{|c|}{ Mother received corticosteroid before delivery } \\
\hline Yes & 291 & 86.61 \\
\hline No & 45 & 13.39 \\
\hline \multicolumn{3}{|l|}{ Maternal serostatus (HIV) } \\
\hline Positive & 15 & 4.46 \\
\hline Negative & 321 & 95.54 \\
\hline
\end{tabular}

ANC, antenatal care; NICU, neonatal intensive care unit.

of death compared with neonates born to multipara mothers (AOR=3.63 ; 95\% CI: 1.59 to 8.24$)$ and neonates born to grand para mothers had 3.2 times $(\mathrm{AOR}=3.21$; 95\% CI: 1.04 to 9.94 ) higher risk of mortality compared with those born to multipara mothers (table 3 ). 
Table 2 Characteristics of preterm neonates admitted in NICU of Ayder and Aksum comprehensive specialised hospitals, northern Ethiopia, $2019(n=336)$

\begin{tabular}{|c|c|c|}
\hline Characteristics & Frequency & Per cent \\
\hline \multicolumn{3}{|l|}{ Place of admission } \\
\hline Ayder & 279 & 83.03 \\
\hline Aksum & 57 & 16.97 \\
\hline \multicolumn{3}{|l|}{ Sex of the neonate } \\
\hline Male & 191 & 56.85 \\
\hline Female & 145 & 43.15 \\
\hline \multicolumn{3}{|l|}{ Gestational age at birth in weeks } \\
\hline Very preterm ( 28 to $<32$ weeks) & 260 & 77.38 \\
\hline $\begin{array}{l}\text { Moderate or late preterm (32 to } \\
<37 \text { weeks) }\end{array}$ & 76 & 22.62 \\
\hline \multicolumn{3}{|l|}{ Birth weight at birth (in grams) } \\
\hline Less than 2500 & 309 & 91.96 \\
\hline 2500 and above & 27 & 8.04 \\
\hline \multicolumn{3}{|c|}{ Feeding initiated during hospitalisation } \\
\hline Yes & 218 & 64.88 \\
\hline No & 118 & 35.12 \\
\hline \multicolumn{3}{|c|}{ Newborn received Kangaroo mother care } \\
\hline Yes & 118 & 35.12 \\
\hline No & 218 & 64.88 \\
\hline \multicolumn{3}{|l|}{ Weight for gestational age at birth } \\
\hline Small & 31 & 9.23 \\
\hline Appropriate & 305 & 90.77 \\
\hline
\end{tabular}

Hypoglycaemic diagnosed at admission

$\begin{array}{lrr}\text { Yes } & 24 & 7.14 \\ \text { No } & 312 & 92.86 \\ \text { Hypothermia diagnosed at admission } & & \\ \text { Yes } & 154 & 45.83 \\ \text { No } & 182 & 54.17\end{array}$

Newborn with clinical diagnosed sepsis

$\begin{array}{ccc}\text { Yes } & 242 & 72.02 \\ \text { No } & 94 & 27.98 \\ \text { Newborn diagnosed with apnoea of prematurity } & \\ \text { Yes } & 14 & 4.17 \\ \text { No } & 322 & 95.83\end{array}$

Perinatal asphyxia diagnosed at birth

\begin{tabular}{|c|c|c|}
\hline Yes & 14 & 4.17 \\
\hline No & 322 & 95.83 \\
\hline \multicolumn{3}{|c|}{ Newborn diagnosed with jaundice } \\
\hline Yes & 37 & 11.01 \\
\hline No & 299 & 88.99 \\
\hline
\end{tabular}

Newborn diagnosed with respiratory distress syndrome

\begin{tabular}{lll} 
Yes & 147 & 43.75 \\
No & 189 & 56.25 \\
\hline
\end{tabular}

NICU, neonatal intensive care unit.

\section{DISCUSSION}

In the present study, the magnitude of preterm hospital neonatal mortality was 28.6 ; $95 \%$ CI (24.0 to 33.7 ). This finding is similar to studies done in Iran $\left(28.7 \%{ }^{43}\right.$ and $27.4 \%)^{28}$ Nigeria $(27.7 \%),{ }^{44}$ Ethiopia $(25.2 \%)^{22}$ and $29.7 \%,{ }^{21}$ and WHO and UNICEF multicounty report $29.3 \% .{ }^{45}$ It was high compared with studies done in Iran $(9.1 \%),{ }^{30}$ Cameroon $(15.7 \%),{ }^{7}$ Ethiopia $\left(18.2 \%{ }^{46}\right.$ and $16.7 \%)^{47}$ and save the children multicounty report $15 \%{ }^{48}$ This could be due to variation in the study population, quality of care provided and difference in the availability of basic interventions, especially surfactant.

However, it was low compared with studies done in Ethiopia $\left(34.9 \%^{24}\right.$ and $\left.36.1 \%\right),{ }^{49}$ South Africa $(64 \%),{ }^{50}$ population-based study done in LMIC $(37.5 \%)^{50}$ and Jordan $(40 \%) .{ }^{51}$ This might be due to the improvement in care in recent years due to access to healthcare service, the accessibility of trained healthcare professionals and the behaviour of the community toward the search and utilisation of health in Ethiopia. ${ }^{52}$

Preterm newborns diagnosed with RDS had a higher risk of death. This finding was in line with studies done in Ethiopia (Gonder ${ }^{40}$ and Jimma ${ }^{24}$ ). Another study conducted in selected Ethiopian hospitals support this finding. ${ }^{53}$ This might be due to the inaccessibility of surfactant treatment in our country, the similarity in the study setting (specialised hospitals), and RDS also leads to acute complications such as pulmonary haemorrhage and intraventricular haemorrhage that increase the risk of mortality. ${ }^{54}$

In this study, KMC had a protective effect on preterm neonatal mortality. This finding was in line with the study done in Gonder, Ethiopia. ${ }^{40}$ This finding was also supported by a systematic review and meta-analysis study that showed that $\mathrm{KMC}$ reduces neonatal mortality. ${ }^{55}$ This might be due to the fact that KMC has the benefit of protecting the newborn from infection, effectively treating hypothermia, improving gastrointestinal function and cardiorespiratory stability and encouraging breast feeding. ${ }^{56}$

Preterm neonates born to nulliparous and grand-parity mothers had high mortality compared with neonates born to multiparty mothers. This finding was supported by studies done in northern Ethiopia, ${ }^{47}$ Uganda $^{57}$ and Australia. ${ }^{58}$ This might be related to nulli and grandparous mothers who are at increased risk of unfavourable newborn outcomes and intrapartum complications. ${ }^{59} 60$

In the present study, preterm neonates who received feeding during their hospital stay had a low risk of mortality. The current finding was supported by studies conducted in Ethiopia. ${ }^{61}{ }^{62}$ This correspondence might be due to colostrum which has an effect on reducing the risk of neonatal infections such as respiratory and gastrointestinal infections, and can also reduce the risk of hypoglycaemic and hypothermia. ${ }^{63}$

Apnoea of prematurity was also identified as a significant predictor of preterm death. It might be due to the potential it has to decrease systematic blood pressure that 
Table 3 Factors associated with preterm in-hospital neonatal mortality in Ayder and Aksum comprehensive specialised hospitals, northern Ethiopia, 2019 ( $n=336)$

\begin{tabular}{|c|c|c|c|c|}
\hline \multirow[b]{2}{*}{ Characteristics } & \multicolumn{2}{|c|}{ Mortality } & \multirow[b]{2}{*}{ COR $(95 \% \mathrm{Cl})$} & \multirow[b]{2}{*}{ AOR $(95 \% \mathrm{Cl})$} \\
\hline & Yes & No & & \\
\hline \multicolumn{5}{|l|}{ Feeding initiated during hospital stay } \\
\hline Yes & 22 & 196 & 0.07 (0.04 to 0.12$)$ & $0.07(0.03 \text { to } 0.15)^{*}$ \\
\hline No & 74 & 44 & 1 & \\
\hline \multicolumn{5}{|l|}{ Maternal residency } \\
\hline Urban & 46 & 145 & 1 & \\
\hline Rural & 50 & 95 & 1.66 (1.03 to 2.67$)$ & 1.68 (0.85 to 3.34$)$ \\
\hline \multicolumn{5}{|l|}{ Hypoglycaemic at admission } \\
\hline Yes & 3 & 21 & 2.97 (0.86 to 10.20$)$ & $1.00(0.12$ to 8.07$)$ \\
\hline No & 93 & 219 & 1 & \\
\hline \multicolumn{5}{|l|}{ Newborn with clinical diagnosed sepsis } \\
\hline Yes & 76 & 166 & 1.69 (0.96 to 2.97$)$ & 1.31 (0.56 to 3.08$)$ \\
\hline No & 20 & 74 & 1 & \\
\hline \multicolumn{5}{|l|}{ Newborn diagnosed with RDS } \\
\hline Yes & 67 & 80 & 4.62 (2.77 to 7.71$)$ & 2.85 (1.35 to 6.00$)^{\star}$ \\
\hline No & 29 & 160 & 1 & \\
\hline \multicolumn{5}{|l|}{ Newborn with apnoea of prematurity } \\
\hline Yes & 8 & 6 & 3.54 (1.19 to 10.51$)$ & $5.45(1.32 \text { to } 22.5)^{\star}$ \\
\hline No & 88 & 234 & 1 & \\
\hline \multicolumn{5}{|l|}{ Newborn received KMC } \\
\hline Yes & 7 & 111 & 0.09 (0.04 to 0.20$)$ & $0.08(0.03 \text { to } 0.20)^{*}$ \\
\hline No & 89 & 129 & 1 & \\
\hline \multicolumn{5}{|l|}{ Birth weight at birth in grams } \\
\hline Less than 2500 & 93 & 216 & 3.44 (1.01 to 11.72$)$ & $3.03(0.62$ to 14.83$)$ \\
\hline 2500 and above & 3 & 24 & 1 & \\
\hline \multicolumn{5}{|l|}{ Gestational age } \\
\hline Very preterm (28 to $<32$ weeks) & 41 & 35 & 4.36 (2.54 to 7.49$)$ & $1.70(0.77$ to 3.74$)$ \\
\hline Moderate or late preterm ( 32 to $<37$ weeks) & 55 & 205 & 1 & \\
\hline \multicolumn{5}{|l|}{ Parity } \\
\hline Nulliparity & 48 & 137 & 1.48 (0.890 to 2.48$)$ & $3.63(1.59 \text { to } 8.24)^{*}$ \\
\hline Multiparity & 38 & 73 & 1 & \\
\hline Grand parity & 10 & 30 & 1.56 (0.69 to 3.53$)$ & 3.21 (1.04 to 9.94$)^{\star}$ \\
\hline
\end{tabular}

*Significantly associated factors.

AOR, adjusted odd ratio; COR, crude odd ratio; KMC, Kangaroo mother care; RDS, respiratory distress syndrome.

leads to hypoperfusion of the brain and hypoxic ischaemic injury, and occurred mainly with desaturation and bradycardic episodes. ${ }^{64}$

Each study has its own limitations. This study had some limitations. First, it was a cross-sectional study that does not show a cause and effect relationship. Second, due to the retrospective nature of the study, some variables were squandered, such as institutional-related factors. Lastly, although our study was a region-wide study, its generalizsability to other settings could be another limitation.

\section{CONCLUSION}

In the current study, the magnitude of neonatal mortality was still high. RDS, apnoea of prematurity, KMC, feeding status and mother parity were significantly associated with preterm in-hospital neonatal mortality. Therefore, to reduce the burden of this problem, it is better to encourage the implementation of KMC and early initiation of feeding. Also, it is better to strengthen early diagnosis and treatment of preterm neonates with RDS and apnoea of prematurity. Furthermore, we recommend 
prospective multicentre studies to identify institutional factors.

\section{Collaborators No.}

Contributors BG was the principal investigator and guarantor who started the research, inscribed the research proposal, piloted the fieldwork, managed data entry, analysed the data and wrote the manuscript. JN critically reviewed, provided essential comments and contributed to the intellectual content of this article and made extensive aids to the conception and manuscript preparation. All authors read and agreed on the final manuscript.

Funding The authors have not declared a specific grant for this research from any funding agency in the public, commercial or not-for-profit sectors.

Competing interests None declared.

Patient and public involvement Patients and/or the public were not involved in the design, or conduct, or reporting or dissemination plans of this research.

\section{Patient consent for publication Not applicable.}

Ethics approval Ethical clearance was obtained from the institutional review board (ERC 1272/2019) the College of Health Sciences of Mekelle University. A permission letter was obtained from the medical director offices of Ayder and Aksum comprehensive specialised hospitals. The study was carried out according to the Declaration of Helsinki. The confidentiality of patient data was safeguarded. Patient data were anonymised before access by study authors. Furthermore, since the data were taken from patient records, consent was not needed; rather, the hospital manager/ authorised gives us the consent besides the participants/neonates.

Provenance and peer review Not commissioned; externally peer reviewed.

Data availability statement Data are available upon reasonable request. The data included in this study are available and can be accessed by contacting the corresponding author through this email address bekahegngi@gmail.com or Bekahegng@du.edu.et.

Open access This is an open access article distributed in accordance with the Creative Commons Attribution Non Commercial (CC BY-NC 4.0) license, which permits others to distribute, remix, adapt, build upon this work non-commercially, and license their derivative works on different terms, provided the original work is properly cited, appropriate credit is given, any changes made indicated, and the use is non-commercial. See: http://creativecommons.org/licenses/by-nc/4.0/.

\section{ORCID iD}

Bekahegn Girma http://orcid.org/0000-0001-5504-6047

\section{REFERENCES}

1 Liu L, Oza S, Hogan D, et al. Global, regional, and national causes of under-5 mortality in 2000-15: an updated systematic analysis with implications for the sustainable development goals. The Lancet 2016;388:3027-35.

2 Organization WH. Levels and trends in child mortality: report 2019 The World Bank; 2019.

3 Liu L, Johnson HL, Cousens S, et al. Global, regional, and national causes of child mortality: an updated systematic analysis for 2010 with time trends since 2000. Lancet 2012;379:2151-61.

4 Tikmani SS, Ali SA, Saleem S, et al. Trends of antenatal care during pregnancy in low- and middle-income countries: findings from the global network maternal and newborn health registry. Paper presented at: seminars in perinatology. Semin Perinatol 2019;43:297-307.

5 Chawanpaiboon S, Vogel JP, Moller A-B, et al. Global, regional, and national estimates of levels of preterm birth in 2014: a systematic review and modelling analysis. Lancet Glob Health 2019;7:e37-46.

6 Liu L, Oza S, Hogan D, et al. Global, regional, and national causes of child mortality in 2000-13, with projections to inform post-2015 priorities: an updated systematic analysis. The Lancet 2015;385:430-40.

7 Ndombo PK, Ekei QM, Tochie JN, et al. A cohort analysis of neonatal hospital mortality rate and predictors of neonatal mortality in a suburban hospital of Cameroon. Ital J Pediatr 2017;43:52.

8 World Health Organization, World Health Organization. International statistical classification of diseases and related health problems. Vol 1. World Health Organization, 2004.

9 Mengesha HG, Lerebo WT, Kidanemariam A, et al. Pre-Term and post-term births: predictors and implications on neonatal mortality in northern Ethiopia. BMC Nurs 2016;15:48.
$10 \mathrm{FMOH}$. Neonatal intensive care unit (NICU) training participants manual: Ethiopia. 201, 4: 46-7.

11 Stephens AS, Lain SJ, Roberts CL, et al. Survival, hospitalization, and acute-care costs of very and moderate preterm infants in the first 6 years of life: a population-based study. $J$ Pediatr 2016;169:e63:61-8.

12 Butler AS, Behrman RE. Preterm birth: causes, consequences, and prevention. National Academies Press, 2007.

13 March of Dimes PMNCH Save the Children WHO. Born too soon: the global action report on preterm birth. In: Howson CP, Kinney MV, Lawn JE, eds. Geneva, 2012.

14 Villar J, Cheikh Ismail L, Victora CG, et al. International standards for newborn weight, length, and head circumference by gestational age and sex: the newborn cross-sectional study of the INTERGROWTH21st project. Lancet 2014;384:857-68.

15 Blencowe H, Lee ACC, Cousens S, et al. Preterm birth-associated neurodevelopmental impairment estimates at regional and global levels for 2010. Pediatr Res 2013;74 Suppl 1:17-34.

16 Mclntire DD, Leveno KJ. Neonatal mortality and morbidity rates in late preterm births compared with births at term. Obstet Gynecol 2008;111:35-41.

17 Kuppusamy N, Balasubramanian M, Krithiga M. Magnitude of preterm admissions in neonatal intensive care unit of rural medical college Hospital. Int J Sci Study 2016;4:284-7.

18 World Health Organization. World health statistics 2016: monitoring health for the SDGs sustainable development goals. World Health Organization, 2016.

19 WHO. WHO recommendations on interventions to improve preterm birth outcomes: evidence base, 2015.

20 Norheim OF, Jha P, Admasu K, et al. Avoiding 40\% of the premature deaths in each country, 2010-30: review of national mortality trends to help quantify the UN Sustainable Development Goal for health. The Lancet 2015;385:239-52.

21 Asmare Y. Survival status and predictor of mortality among premature neonate that was admitted to neonatal intensive care unit from 2013-2017 at Tikur Anbessa Hospital, Addis Ababa Ethiopia:conference presentation. In: Annual child and family healthcare nursing conference. Bali, Indonesia, 2018.

22 Yehuala S, Teka Z. Survival analysis of premature infants admitted to neonatal Int ensive care unit (NICU) in Northwest Ethiopia using Semi-Parametric Fr ailty model. Journal of Biometrics \& Biostatistics 2015;6:1):1

23 Yismaw AE, Gelagay AA, Sisay MM. Survival and predictors among preterm neonates admitted at University of Gondar comprehensive specialized hospital neonatal intensive care unit, Northwest Ethiopia. Ital J Pediatr 2019;45:4.

24 Wesenu M, Kulkarni S, Tilahun T. Modeling determinants of time-to-death in premature infants admitted to neonatal intensive care unit in Jimma university specialized hospital. Ann. Data. Sci. 2017;4:361-81.

25 Gargari SS, Kashanian M, Zendedel H, et al. Survival and risk factors of extremely preterm babies (<28 weeks) in the three Iranian hospitals. Acta Medica Iranica 2018;56:181-8.

26 Castro ECMde, Leite Álvaro Jorge Madeiro, Almeida MFBde, et al. Perinatal factors associated with early neonatal deaths in very low birth weight preterm infants in northeast Brazil. BMC Pediatr 2014;14:312.

27 Schindler T, Koller-Smith L, Lui K, et al. Causes of death in very preterm infants cared for in neonatal intensive care units: a population-based retrospective cohort study. BMC Pediatr 2017;17:59.

28 Basiri B, Esna Ashari F, Shokouhi M, et al. Neonatal mortality and its main determinants in premature infants hospitalized in neonatal intensive care unit in Fatemieh Hospital, Hamadan, Iran. J Compr Ped 2015;6.

29 Abdel-Latif ME, Bajuk B, Oei J, et al. Does rural or urban residence make a difference to neonatal outcome in premature birth? A regional study in Australia. Arch Dis Child Fetal Neonatal Ed 2006;91:F251-6.

30 Haghighi L, Nojomi M, Mohabbatian B, et al. Survival predictors of preterm neonates: hospital based study in Iran (2010-2011). Iran J Reprod Med 2013;11:957-64.

31 Marchant T, Willey B, Katz J, et al. Neonatal mortality risk associated with preterm birth in East Africa, adjusted by weight for gestational age: individual participant level meta-analysis. PLoS Med 2012;9:e1001292.

32 Kong X, Xu F, Wu R, et al. Neonatal mortality and morbidity among infants between 24 to 31 complete weeks: a multicenter survey in China from 2013 to 2014. BMC Pediatr 2016;16:174.

33 Lawn JE, Blencowe H, Oza S, et al. Every newborn: progress, priorities, and potential beyond survival. Lancet 2014;384:189-205. 
34 CSA-Ethiopia I. International: Ethiopia demographic and health survey 2011. Addis Ababa, Ethiopia and Calverton, Maryland, USA Central Statistical Agency of Ethiopia and ICF International, 2012.

$35 \mathrm{FMOH}$. National newborn and child survival strategy document brief summary 2015/16-2019/20, 2015

36 UNICEF, WHO, World bank organization, UN. Levels \& Trends in Estimates developed by the UN Inter-agency Group for Child Mortality Estimation Child Mortality 2018 report. Geneva, Switzerland, 2018.

37 Institute EPH, ICF. Ethiopia mini demographic and health survey 2019: key indicators. Rockville, Maryland, USA: EPHI and ICF, 2019.

38 EDHS E. Demographic and health survey 2016: key indicators report The DHS Program ICF; 2016: 363-4.

39 Trh bureau. Demographic data of Tigray region and public health facilities, 2019.

40 Yismaw AE, Tarekegn AA. Proportion and factors of death among preterm neonates admitted in University of Gondar comprehensive specialized hospital neonatal intensive care unit, Northwest Ethiopia. BMC Res Notes 2018;11:867.

41 McManus BM, Chambliss JH, Rapport MJ. Application of the NICU practice guidelines to treat an infant in a level III NICU. Pediatr Phys Ther 2013;25:204-13.

42 Carter BS, Haverkamp AD, Merenstein GB. The definition of acute perinatal asphyxia. Clin Perinatol 1993;20:287-304.

43 Ghorbani F, Heidarzadeh M, Dastgiri S. Survival of premature and low birth weight infants: a multicenter, prospective, cohort study in Iran. Iran J Neonatol 2017;8:16-22.

44 Bako B, Idrisa A, Garba MA, et al. Determinants of neonatal survival following preterm delivery at the University of Maiduguri teaching Hospital, Maiduguri, Nigeria. Trop J Obstet Gynaecol 2017;34:39.

45 World Health Organization. Countdown to 2015 decade report (20002010) with country profiles: taking stock of maternal, newborn and child survival World Health Organization; 2010.

46 Debelew GT, Afework MF, Yalew AW. Determinants and causes of neonatal mortality in Jimma zone, Southwest Ethiopia: a multilevel analysis of prospective follow up study. PLoS One 2014;9:e107184.

47 Hadgu FB, Gebretsadik LG, Mihretu HG, et al. Prevalence and factors associated with neonatal mortality at Ayder comprehensive specialized Hospital, Northern Ethiopia. A cross-sectional study. Pediatric Health Med Ther 2020;11:29-37.

48 Lawn JE, Kinney MV, Black RE, et al. Newborn survival: a multicountry analysis of a decade of change. Health Policy Plan 2012;27 Suppl 3:iii6-28

49 Tamene A, Abeje G, Addis Z. Survival and associated factors of mortality of preterm neonates admitted to Felege Hiwot specialized hospital, Bahir Dar, Ethiopia. SAGE Open Med 2020;8:205031212095364.
50 Ballot DE, Chirwa TF, Cooper PA. Determinants of survival in very low birth weight neonates in a public sector hospital in Johannesburg. BMC Pediatr 2010;10:30.

51 Abdel Razeq NM, Khader YS, Batieha AM. The incidence, risk factors, and mortality of preterm neonates: a prospective study from Jordan (2012-2013). Turk J Obstet Gynecol 2017;14:28

52 Federal Democratic Republic of Ethiopia Ministry of Health. Ethiopian health care quality Bulletin continuous health care quality improvement through knowledge management. Addis Ababa, 2019.

53 Muhe LM, McClure EM, Nigussie AK, et al. Major causes of death in preterm infants in selected hospitals in Ethiopia (SIP): a prospective, cross-sectional, observational study. Lancet Glob Health 2019;7:e1130-8.

54 Reuter S, Moser C, Baack M. Respiratory distress in the newborn. Pediatr Rev 2014;35:417.

55 Lawn JE, Mwansa-Kambafwile J, Horta BL, et al. 'Kangaroo mother care' to prevent neonatal deaths due to preterm birth complications. Int J Epidemiol 2010;39 Suppl 1:i144-54.

56 World Health Organization. WHO recommendations on interventions to improve preterm birth outcomes: evidence base. World Health Organization, 2015.

57 Kananura RM, Tetui M, Mutebi A, et al. The neonatal mortality and its determinants in rural communities of eastern Uganda. Reprod Health 2016;13:13.

58 Bai J, Wong FWS, Bauman A, et al. Parity and pregnancy outcomes. Am J Obstet Gynecol. 2002;186:274. 02/02.

59 Yousfani S, Bibi S, Mumtaz F. Perinatal mortality and related obstetric risk factors at a tertiary care hospital of Hyderabad. J Liaquat Univ Med Health Sci 2008;7:204-7.

60 Hoque M, Hoque E, Kader SB. Pregnancy complications of Grandmultiparity at a rural setting of South Africa. Int J Reprod BioMed 2008;6.

61 Alebel A, Wagnew F, Petrucka P, et al. Neonatal mortality in the neonatal intensive care unit of Debre Markos referral hospital, Northwest Ethiopia: a prospective cohort study. BMC Pediatr 2020;20:72

62 Desalew A, Sintayehu Y, Teferi N, et al. Cause and predictors of neonatal mortality among neonates admitted to neonatal intensive care units of public hospitals in eastern Ethiopia: a facility-based prospective follow-up study. BMC Pediatr 2020;20:1-11.

63 Dieterich CM, Felice JP, O'Sullivan E, et al. Breastfeeding and health outcomes for the mother-infant dyad. Pediatr Clin North Am 2013;60:31.

64 Pichler G, Urlesberger B, Müller W. Impact of bradycardia on cerebral oxygenation and cerebral blood volume during apnoea in preterm infants. Physiol Meas 2003;24:671. 